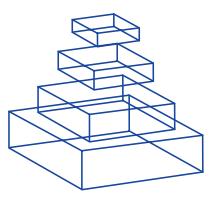

\title{
Relationship of hippocampal theta and gamma oscillations to potentiation of synaptic transmission
}

\author{
Arthur Bikbaev ${ }^{1}$ and Denise Manahan-Vaughan ${ }^{1,2, \dagger}$ \\ 1 Department of Experimental Neurophysiology, Medical Faculty, Ruhr University Bochum, Bochum, Germany. \\ 2 International Graduate School of Neuroscience, Ruhr University Bochum, Bochum, Germany.
}

Edited by:

Carmen Sandi, Ecole

Polytechnique Fédérale

de Lausanne, Switzerland

Reviewed by:

Bruno Poucet, CNRS and

Université de Provence, France

Alexander Dityatev, Italian

Institute of Technology, Italy

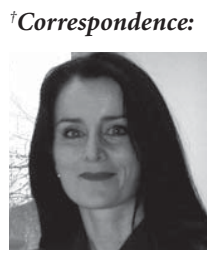

Denise Manahan-Vaughan completed her doctoral degree at Trinity College Dublin and started her research career in Germany in the mid 90's. She is Chair of the Department of Neurophysiology at the Medical Faculty of the RUB. Currently she is a member of the executive committee of the Federation of European Neuroscience Societies and chair of the Network of European Neuroscience Schools. Her research

focusses especially on studies of the role of hippocampal synaptic plasticity in memory processes, using a combined in vivo electrophysiological, behavioural and molecular methodological approach. denise.manahan-vaughan@ rub.de

In the hippocampus in vivo, both synaptic plasticity and network activity are closely interdependent. We have found that immediately after an attempt to induce long-term potentiation (LTP), changes in theta $(5-10 \mathrm{~Hz})$ and gamma $(30-100 \mathrm{~Hz})$ activity correlate tightly with the occurrence of LTP, suggesting that tetanisation-driven activation of sensory inputs synchronises the activity of granule cells and interneurons, and thus, facilitates the encoding of acquired stimuli. This results in increase of theta and gamma power, and elevates the probability that afferent stimuli both coincide with the peak of theta cycle and reach their post-synaptic target within the gamma time-window (of 10-30 ms). Both these mechanisms can effectively shift the direction, of tetanisation-induced changes in synaptic weight, towards potentiation and induction of LTP. Here, we discuss our findings in the context of possible mechanisms that link theta and gamma oscillations with LTP induction, as well as their role in information processing and formation of memories.

Keywords: LTP, theta, gamma, network activity, oscillations, synaptic plasticity, tetanisation, in vivo

\section{LONG-TERM POTENTIATION OF SYNAPTIC TRANSMISSION AS A MODEL OF SYNAPTIC PLASTICITY}

The ability to analyse and learn new information and, if necessary, modify ongoing behaviour, based on a combination of previous and recent memories, is an important factor for the survival of organisms in an ever-changing world. Creating and managing these memory traces, comprise core functions of the central nervous system, which rely on its ability to engage in synaptic plasticity. They can be monitored at different levels, ranging from the subcellular to the behavioural.

Since its discovery in the late 1960s (Andersen and Lømo, 1967; Bliss and Lømo, 1973; see for review: Lømo, 2003), long-term potentiation (LTP) has been the subject of intense study, using a plethora of induction protocols, species, and various preparations both in vivo and in vitro. Nowadays, LTP, along with long-term depression (LTD), is widely used as a model of synaptic information storage and are believed to represent the processes of learning and memory in neuronal networks (Abraham, 2003; Bear, 1996; Bliss and Collingridge, 1993; Kemp and Manahan-Vaughan, 2007; Lynch, 2004; Whitlock et al., 2006).

Synaptic plasticity in the form of LTP, typically results in both functional and structural reorganisation of the synapse, that evolves over time and comprises different phases, namely LTP-induction (post-tetanic potentiation), short-term potentiation, LTP expression (early LTP) and maintenance (late LTP) (Abraham, 2003; Bliss and Collingridge, 1993; Frey et al., 1993; Huang et al., 1996; Nguyen et al., 1994). Furthermore, each of these phases is characterised by the different involvement of neuro- 
transmitter systems acting via both ionotropic and metabotropic receptors. For the induction phase, several lines of evidence underlie the important role of the activation of N-methyl-D-aspartate (NMDA) receptors, at least for the hippocampal CA1 region and dentate gyrus (Abraham and Mason, 1988; Collingridge et al., 1983; Errington et al., 1987; Fox et al., 2006; Frey et al., 1996; Manahan-Vaughan, 1997; Niewoehner et al., 2007). For early LTP, activation of the metabotropic glutamate receptors (mGluRs), particularly group I mGluRs, plays a critical role (Aiba et al., 1994; Anwyl, 1999; Manahan-Vaughan, 1997; Manahan-Vaughan and Braunewell, 2005; Manahan-Vaughan and Reymann, 1996; Manahan-Vaughan et al., 1998; Richter-Levin et al., 1994). Late-LTP (maintenance phase) requires de novo protein synthesis (Frey et al., 1996; Krug et al., 1984; Otani and Abraham, 1989) and activation of several immediate-early genes and late-response genes (Abraham et al., 1991; Brakeman et al., 1997; Cole et al., 1989; Link et al., 1995; Messaoudi et al., 2007; Wisden et al., 1990; Yin et al., 2002). Additionally, various neuromodulators can either increase or decrease the probability, magnitude and/or longevity of changes in synaptic transmission, hence affecting the outcomes of patterned synaptic activation (Granado et al., 2008; Kemp and Manahan-Vaughan, 2005, 2008; Kulla and Manahan-Vaughan, 2002; Lemon and Manahan-Vaughan, 2006; Li et al., 2003, 2007; Manahan-Vaughan and Kulla, 2003; Swanson-Park et al., 1999).

Besides the different relative involvement of neurotransmitter systems, the induction and/or expression of LTP, as a reflection of central synapses to acquire, process and subsequently store new information, depends upon several other factors, including environmental enrichment, various forms of stress, etc. (Artola et al., 2006; Avital et al., 2006; Bruel-Jungerman et al., 2005; Duffy et al., 2001; Foster et al., 2000; Kopp et al., 2006; Seidenbecher et al., 1997; van Praag et al., 1999; Xu et al., 1998), which couple the sensory input to a current behavioural state and provide the contextual frame for processing of sensory stimuli. Thus, taking into account the plethora of mechanisms underlying the phenomenon of LTP, it is not surprising that various factors and/or experimental manipulations can markedly affect its different phases. However, for most forms of LTP, and particularly for electrically induced LTP, the state of the animal (synaptic and behavioural) during a short period of time, both during and immediately after tetanisation, appears decisive in determining the persistence of potentiation (Abraham, 2003).

In our study (Bikbaev and Manahan-Vaughan, 2007), we applied high-frequency tetanisation
(HFT) in freely behaving adult rats and monitored field excitatory synaptic potentials (fEPSPs) in parallel with the intrahippocampal electroencephalogram over a period of $24 \mathrm{~h}$. Despite the fact that an identical stimulation protocol was employed for all animals, substantial variation in the outcomes of tetanisation was found. In the first group of animals, a robust LTP occurred that was stable for at least $24 \mathrm{~h}$ (LTP group), in the second group shortterm potentiation that endured for up to $3 \mathrm{~h}$ was induced (STP group), whereas in the third group a failure of potentiation occurred, i.e. no persistent increase in synaptic transmission was seen (failure group). Given this range of tetanisation results, we analysed them in the context of the changes in network activity that occurred during and within first $300 \mathrm{~s}$ after tetanisation.

\section{TETANISATION-TRIGGERED FACILITATION OF THETA AND GAMMA ACTIVITY FAVOURS LTP}

Oscillatory activity is an integral part of functional neuronal networks, and significant variability in patterns of oscillatory activity can be registered under certain conditions both in vivo and in vitro. Modification of synaptic weights occurs very fast during the activated state of the hippocampus (Buzsáki, 1996), with entorhinal-hippocampal network oscillations at theta frequency playing a crucial role in this process (Kamondi et al., 1998). Particularly in the hippocampus, theta oscillations (theta rhythm, rhythmic slow activity) have been proposed to play a role in a wide variety of hippocampal functions (see for review: Buzsáki, 2005). In rodents, periods of prominent theta oscillations occur during exploratory behaviour and phases of rapid eye movement REM (sleep); conditions which are generally termed theta-associated behaviour (Bland, 1986; Buzsáki, 2002, 2005; Vanderwolf, 1969). These behavioural states, and particularly exploratory behaviour, are characterised by neocortico-hippocampal transfer of new spatial information when acquisition and/or encoding of sensory information should be facilitated, whereas transfer of the information from the hippocampus to neocortex is associated with other patterns, such as sharp waves and ripples (Bragin et al., 1995; Buzsáki, 1996; Buzsáki et al., 2002; Chrobak et al., 2000). Gamma oscillatory activity represents another pattern of network activity, which is characteristic for cortical locations, and is proposed to be involved in various cognitive functions (Buzsáki and Chrobak, 1995; Fell et al., 2001; Fries et al., 2001; Gray and Singer, 1989; Hermann et al., 2004; Hopfield, 1995; Lisman, 1999; Lisman and Idiart, 1995; Montgomery and Buzsáki, 2007; Singer, 1993). In the hippocampus of freely mov- 
ing animals, the amplitude of gamma oscillations is higher in the dentate gyrus than in other hippocampal regions expressing gamma oscillations (Bragin et al., 1995), and varies as a function of the theta cycle (Csicsvari et al., 2003; Penttonen et al., 1998). Hence, hippocampal theta and gamma oscillations comprise functionally-associated patterns of network activity that emerge as a consequence of the combination of intrinsic oscillatory properties of principal cells and interneurons, the rhythmic activation of which is driven by intra- and extrahippocampal connections (Bartos et al., 2007; Bragin et al., 1995; Csicsvari et al., 2003; Klausberger et al., 2003; Penttonen et al., 1998; Ylinen et al., 1995).

The results of our study demonstrated that the successful potentiation of synaptic transmission (LTP and STP groups) in freely moving rats, was preceded by a higher relative theta power in the period of $300 \mathrm{~s}$ after HFT, when compared with the pre-tetanisation period (Figure 1). In contrast, a gradual recovery of theta power to pretetanisation values, but not an increase, was found in the LTP-failure group. In other words, successful induction of potentiation (either in the form of STP or LTP), resulted in an enhancement of theta oscillatory activity after tetanisation, whereas no such enhancement occurred in rats that showed failure of LTP. The mean amplitude of a single theta cycle was also significantly higher within the posttetanisation period in the LTP and STP groups, when compared to the group of failed synaptic potentiation. Taken together, these data suggest that a transient increase of theta power is necessary for the proper handling of sensory input activation (mimicked here by HFT). This, in turn, may play a permissive role in LTP induction, and, in general, in the formation of memory trace(s) of newly acquired information.

However, the differences between LTP, STP and failed potentiation groups were not limited in our study by theta oscillations. We found that within the first $100 \mathrm{~s}$ after HFT the increase in theta power, and the mean amplitude of a single theta cycle, was accompanied by higher gamma power in the LTP group, and higher amplitude of gamma oscillations within a single theta cycle in both the LTP and STP groups, when compared with cases of failed potentiation (Figure 1B). This indicates that not the increase of theta power per se, but a correlated increase of both theta and gamma power is important for enabling or mediating the plastic changes in synaptic weights. Furthermore, our results show that these enhancements of oscillatory activity should take place within a relatively short period of time for synaptic plasticity to occur. Taking into account that the amplitude of gamma oscillations in the dentate gyrus, but not in the CA3 or CA1 regions, is significantly higher in the presence of theta oscillations than in non-theta states (Csicsvari et al., 2003), these findings suggest that the tetani-

A

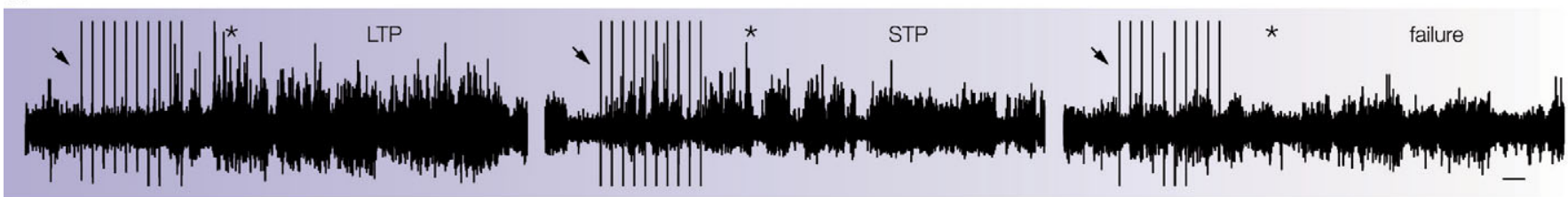

B
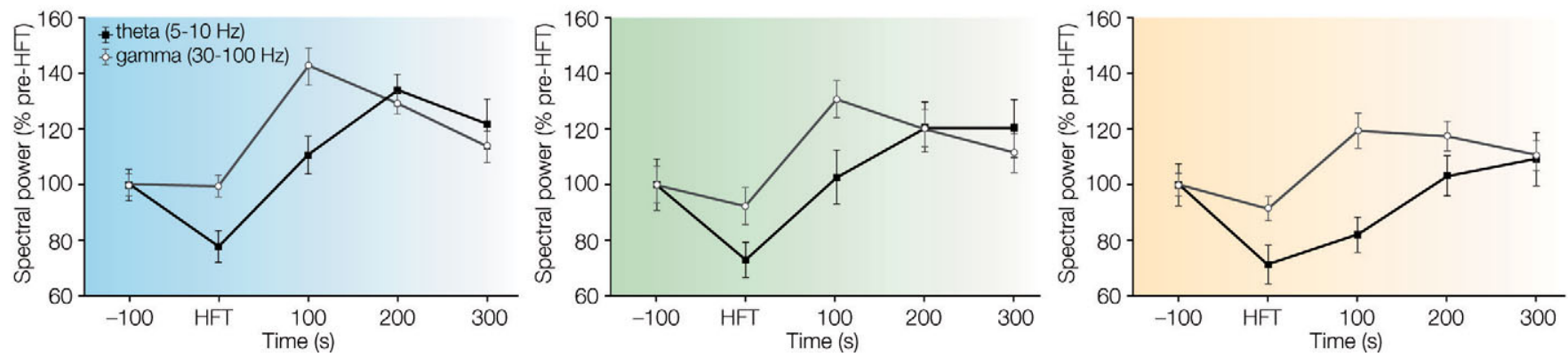

Figure 1 I Transient enhancement of theta and gamma power in the post-tetanisation period correlates with potentiation of synaptic transmission in the dentate gyrus of freely moving rats. (A) Examples of EEG epochs, which comprise $100 \mathrm{~s}$ long periods of tetanisation $(200 \mathrm{~Hz}, 10 \mathrm{trains}$ : first train is marked by arrow) and following $300 \mathrm{~s}$, recorded in rats that showed either LTP (left panel), STP (middle panel) or failure of potentiation (right panel), respectively. Asterisk denotes the period immediately after HFT, when the amplitude of network oscillations is higher in LTP and STP cases, in comparison with failed potentiation. Scale bar: $20 \mathrm{~s}$. (B) Successful potentiation (LTP and STP) of synaptic transmission is associated with a prominent increase of the relative theta and gamma power particularly in the period encompassing $100 \mathrm{~s}$ after tetanisation. The results were pooled for LTP, STP and failure groups and presented as Mean \pm S.E.M. (modified from Bikbaev and Manahan-Vaughan, 2007). 
sation-induced facilitation of theta activity can play a causal role for the enhancement of gamma oscillations.

In the dentate gyrus of the intact brain, the power of both theta and gamma activity is driven by and strongly depends upon entorhinal input, and is higher during exploratory behaviour (Bragin et al., 1995; Csicsvari et al., 2003). Furthermore, behavioural data indicating enhanced eyeblink conditioning in rabbits that received pairings of stimuli during epochs of prominent theta activity, when compared to those stimulated during non-theta periods (Seager et al., 2002), provide additional support for a facilitatory role of theta oscillations in learning. However, one should emphasise that the increase of theta power occurred in our study in the period after tetanisation. Thus, the differences in theta power that we observed, did not comprise an endogenous pre-condition for synaptic plasticity, but rather occurred as a consequence of perforant path stimulation. Accordingly, if natural theta rhythm is necessary for the acquisition or processing of sensory stimuli, one can presume that the artificial activation of sensory inputs (in the form of HFT) would require and/or induce an enhancement of oscillatory activity in the theta frequency range, in order to temporally organise neuronal activity and favour synaptic plasticity. The depolarisation of dendritic compartments of dentate gyrus granule cells via activation of NMDA receptors and mGluRs, after strong activation of the glutamatergic perforant path, is likely to contribute to such an enhancement. Perforant path stimulation of the dentate gyrus, in conjunction with subsequent firing of mossy fiber collaterals, will also activate parvalbumin-expressing basket cells (Kneisler and Dingledine, 1995), which via ionotropic $\gamma$-aminobutyric acid $\left(\mathrm{GABA}_{\mathrm{A}}\right)$ receptors provide rhythmic inhibition of somata and perisomatic region of principal cells and play a pivotal role in the generation of both theta (Buzsáki, 2002; Klausberger et al., 2003; Sik et al., 1997; Ylinen et al., 1995) and gamma (Bartos et al., 2001, 2007; Penttonen et al., 1998; Vida et al., 2006) oscillations. Additionally, activation of $\mathrm{GABA}_{\mathrm{A}}$ receptors has been reported to be critical also for the generation of transient tetanically induced gamma oscillations in vitro (Traub et al., 2004; Whittington et al., 1997). Hence, the combination of NMDAR-induced dendritic excitation and $\mathrm{GABA}_{\mathrm{A}} \mathrm{R}$-mediated somatic inhibition results in current flow through distal dendrites, which is important for the generation and maintenance of extracellular theta currents (Buzsáki, 2002). This could also effectively trigger and/or enhance theta oscillations in post-HFT period. In turn, theta oscillations may dynamically modulate the probability of NMDAR activation, which is highest on the peak of the theta cycle and the lowest on the trough (Vertes, 2005). The increase of gamma power in the post-tetanisation period may rely on the activation of group I mGluRs, which was reported to induce $\mathrm{GABA}_{\mathrm{A}} \mathrm{R}$-dependent gamma oscillations in vitro (Whittington et al., 1995), and increase gamma power in vivo (Martin, 2001). We have found recently that prolonged inhibition of mGluR5 results in a significant impairment of LTP associated with a marked suppression of gamma oscillations in the dentate gyrus of freely moving rats (Bikbaev et al., 2008). Taken together, correlated activation of granule cells and interneurons, via fast and slow glutamatergic excitation, not only can contribute to long-term synaptic potentiation, but, complemented with fast rhythmic GABAergic inhibition, can affect network oscillations on both short- and long-term time-scales (Figure 2). In this respect, pharmacological modulation of selected neurotransmitter systems, including the glutamatergic, GABAergic and cholinergic systems, coupled with correlation analysis of network activity and long-term changes in synaptic transmission, would be necessary for a more conclusive support of this suggestion. For instance, such analysis after activation of the cholinergic system, which can facilitate oscillatory activity in the theta frequency band, and simultaneous inhibition of $\mathrm{GABA}_{\mathrm{A}} \mathrm{R}$ and/or mGluR-mediated signalling, which affects hippocampal gamma activity, could help to dissect the roles of theta and gamma oscillations in the shaping of synaptic plasticity.

\section{THE DIRECTION OF CHANGE IN SYNAPTIC WEIGHT CORRELATES WITH THE PHASE OF THETA CYCLE}

The apparent relationship between theta activity and certain types of behaviour, and the relative regularity and stability of this oscillatory pattern suggests that theta rhythm may serve as an internal timing mechanism for individual elements of spatially distributed neuronal ensembles (Buzsáki, 2005). In other words, enhanced theta oscillations may provide an appropriate time-window for the firing of individual neurons within currently activated ensemble(s) and, therefore, optimise the encoding of the acquired signal. Indeed, the firing rate of both principal cells and several classes of interneurons in the hippocampus has been found to be theta phaselocked, i.e. to depend upon the phase of the ongoing theta cycle (Csicsvari et al., 1999; Klausberger et al., 2003; O'Keefe and Recce, 1993). An important link between hippocampal theta oscillations and the probability of potentiation of synaptic transmission is provided by observations with regard to increases or decreases of synaptic efficacy, which were caused 
Perforant path activation $(200 \mathrm{~Hz}$ high-frequency tetanisation)

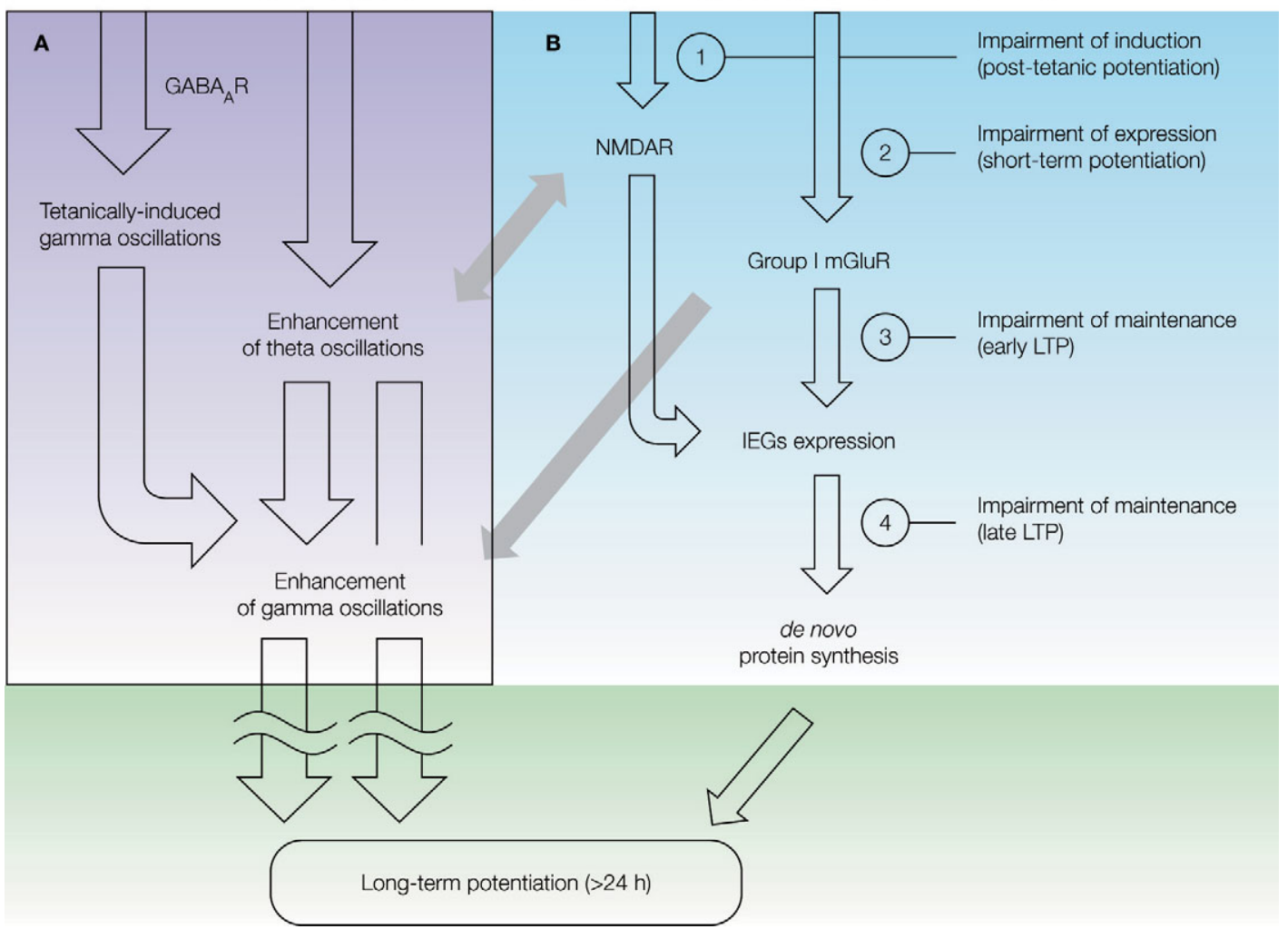

Figure 2 | A schematic representation of the consequences of high-frequency tetanisation that occur on the network and cellular levels, and lead towards long-term potentiation of synaptic transmission. (A) Strong afferent stimulation results in an enhancement of both theta and gamma oscillations, which occurs within 5 min interval after tetanisation and can be mediated via GABARs, NMDARs and mGluRs. (B) Tetanisation-triggered activation of both ionotropic and metabotropic glutamate receptors is followed by the expression of plasticity-related immediate-early genes (IEGs) and protein synthesis, which can underlie structural synaptic reorganisation and long-term increase in synaptic efficacy. Experimental procedures that inhibit the induction, expression or maintenance of LTP can result in impairment of post-tetanic potentiation, STP, early LTP or late LTP (1-4, respectively). Grey arrows denote possible links between NMDAR and mGluR activation and facilitation of network activity in theta and gamma frequency bands.

by trains of high-frequency stimulation delivered either at the peak or the trough of theta cycle, and which resulted in LTP or LTD respectively (Huerta and Lisman, 1993, 1995; McCartney et al., 2004; Pavlides et al., 1988). During naturally occurring, locomotion-induced theta oscillations, LTP, that persists for at least $48 \mathrm{~h}$, is preferentially induced by stimuli delivered near the local theta peak in behaving animals (Hyman et al., 2003; Orr et al., 2001), whereas in anesthetised animals a long-lasting enhancement of fEPSP is elicited, if hippocampal afferents are stimulated synchronously on the peak of theta oscillations (Hölscher et al., 1997; Pavlides et al., 1988). This demonstrates that not only the parameters of the stimulation protocol, but also the timing of tetanisation relative to the phase of theta cycle, can change the direction of synaptic plasticity (LTD vs. LTP).

Thus, tetanisation-driven increases of theta and gamma oscillations, such as those observed in our study (Bikbaev and Manahan-Vaughan, 2007), seem to be intrinsically interconnected, and play complementary roles in synaptic potentiation. The heightened theta power in the period after tetanisation is likely to temporally organise the firing of principal cells within theta time-windows, hence supporting the increase of the amplitude of gamma oscillations. Bearing in mind that the higher amplitude of gamma oscillations reflects a higher degree of synchronisation in the network (see for review: Axmacher et al., 2006), the increase of gamma power in the period immediately after tetanisation may indicate that, during the facilitated theta activity, the firing of principal cells and interneurons is more synchronised (or precise) and/or recruits more elements into the network activity. Accordingly, enhanced gamma oscillations synchronise neuronal firing within narrower gamma time windows and elevate the probability for afferent stimuli to coincide with the peak of theta cycle, where the 
gamma amplitude is highest, hence resulting in the strengthening of the activated synaptic pathway. The outcomes of studies of spike-timing dependent plasticity (see for review: Dan and Poo, 2004) demonstrate that such synchronisation of neuronal spiking, within a 10-30 ms window: which precisely matches to a single gamma cycle, can dramatically increase the probability of potentiation of activated synaptic connections. Moreover, in in vitro recordings from the primary visual cortex, where theta activity is generally not so prominent as in the hippocampus, pairing the stimuli with either the peak or trough of oscillations in the beta and gamma frequency ranges has been found to effectively drive synaptic plasticity towards potentiation or depression, respectively (Wespatat et al., 2004).

In this context, one can conclude that the transient enhancement of theta and gamma oscillations in the post-tetanisation period reflects the engagement of the system in encoding of acquired information. This can result in a subsequent "reconfiguration" of the network, coupled with the strengthening of currently activated connections, and the weakening of the others. Furthermore, facilitated theta activity can support a tighter timing control of the firing of principal cells and interneurons in the network, which serves to optimise information processing. Tetanisation-triggered enhancement of gamma oscillations is associated, on the other hand, with higher synchronisation and reflects the coordinated ensemble activity aimed to encode/retrieve relevant memories. Accordingly, the absence or inconsistency of such changes in network activity can be related to the lack, or insufficiency, of activation of required neurotransmitter systems, sub-optimal conditions for the processing of sensory information and, therefore, a lower probability for LTP.

\section{SUMMARY}

For several decades, theta rhythm was regarded in rodents as an electrographic hallmark of exploratory behaviour, that occurs when the hippocampus is engaged in the acquisition and processing of sensory stimuli, which can lead in turn to experience-based modification of ongoing behaviour. Gamma oscillations were also proposed to play a role in various cognitive processes both in human and animals. At the neuronal level, the acquisition and formation of memory traces are believed to rely on activity-related changes in synaptic efficacy, and LTP of synaptic transmission after patterned afferent stimulation is considered as an adequate experimental model of these processes. However, despite the existence of extensive experimental data showing the involvement of hippocampal theta and gamma oscillations in cognitive processes, a relationship between the coordinated enhancement of both theta and gamma power immediately after tetanisation and the consequences of induction of synaptic plasticity in freely moving rats was not, to our knowledge, described earlier. We found that changes in theta and gamma oscillatory activity precede electrically induced potentiation of synaptic transmission. Importantly, the correlated tetanisation-driven enhancement of both theta and gamma oscillations is associated with successful short- and LTP, but not with its failure. These findings link LTP with the oscillatory activity of rather large assemblies of hippocampal principal cells and interneurons, and provide additional support for the role of hippocampal theta and gamma oscillations in information processing and the formation of new memories.

\section{CONFLICT OF INTEREST STATEMENT}

The authors declare that the research was conducted in the absence of any commercial or financial relationships that could be construed as a potential conflict of interest.

\section{ACKNOWLEDGEMENT}

This work was supported by a Deutsche Forschungsgemeinschaft grant to D. ManahanVaughan (Ma1843).

\section{REFERENCES}

Abraham, W. C. (2003). How long will long-term potentiation last? Philos. Trans. R. Soc. Lond., B, Biol. Sci. 358, 735-744.

Abraham, W. C., Dragunow, M., and Tate, W. P. (1991). The role of immediate early genes in the stabilisation of long-term potentiation. Mol. Neurobiol. 5, 297-314.

Abraham, W. C., and Mason, S. E. (1988). Effects of the NMDA receptor/channel antagonists CPP and MK801 on hippocampal field potentials and long-term potentiation in anesthetized rats. Brain Res. 462, 40-46.

Aiba, A., Chen, C., Herrup, K., Rosenmund, C. Stevens, C. F., and Tonegawa, S. (1994). Reduced hippocampal long-term potentiation and context-specific deficit in associative learning in mGluR1 mutant mice. Cell 79, 365-375.

Andersen, P., and Lømo, T. (1967). Control of hippocampal output by afferent volley frequency. Prog. Brain Res. 27, 400-412.

Anwyl, R. (1999). Metabotropic glutamate receptors: electrophysiological properties and role in plasticity. Brain Res. Rev. 9, 83-120.

Artola, A., von Frijtag, J. C., Fermont, P. C., Gispen, W. H., Schrama, L. H., Kamal, A., and Spruijt, B. M. (2006). Long-lasting modulation of the induction of LTD and LTP in rat hippocampal CA1 by behavioural stress and environmental enrichment. Eur. J. Neurosci. 23, 261-272.
Avital, A., Segal, M., and Richter-Levin, G. (2006). Contrasting roles of corticosteroid receptors in hippocampal plasticity. J. Neurosci. 26, 9130-9134.

Axmacher, N., Mormann, F., Fernandez, G., Elger, C. E., and Fell, J. (2006). Memory formation by neuronal synchronization. Brain Res. Rev. $52,170-182$.

Bartos, M., Vida, I., Frotscher, M., Geiger, J. R., and Jonas, P. (2001). Rapid signaling at inhibitory synapses in a dentate gyrus interneuron network. J. Neurosci. 21, 2687-2698.

Bartos, M., Vida, I., and Jonas, P. (2007). Synaptic mechanisms of synchronized gamma oscillations in inhibitory interneuron networks. Nat. Rev. Neurosci. 8, 45-56. 
Bear, M. F. (1996). A synaptic basis for memory storage in the cerebral cortex. Proc. Natl. Acad. Sci. USA 93, 13453-13459.

Bikbaev, A., and Manahan-Vaughan, D. (2007). Hippocampal network activity is transiently altered by induction of long-term potentiation in the dentate gyrus of freely behaving rats. Front. Behav. Neurosci. doi: 10.3389/neuro.08/007.2007.

Bikbaev, A., Neyman, S., Ngomba, R. T., Conn, P. J., Nicoletti, F., and Manahan-Vaughan, D. (2008). MGluR5 mediates the interaction between lateLTP, network activity, and learning. PLoS ONE 3, e2155.

Bland, B. H. (1986). The physiology and pharmacology of hippocampal formation theta rhythms. Prog. Neurobiol. 26, 1-54.

Bliss, T. V., and Collingridge, G. L. (1993). A synaptic model of memory: long-term potentiation in the hippocampus. Nature 361, 31-39.

Bliss, T. V. P., and Lømo, T. (1973). Long-lasting potentiation of synaptic transmission in the dentate area of the unanaesthetized rabbit following stimulation of the perforant path. J. Physiol. 232, 357-373.

Bragin, A., Jandó, G., Nádasdy, Z., Hetke, J., Wise, K., and Buzsáki, G. (1995). Gamma (40-100 Hz) oscillation in the hippocampus of the behaving rat. J. Neurosci. 15, 47-60.

Brakeman, P. R., Lanahan, A. A., O’Brien, R., Roche, K., Barnes, C. A., Huganir, R. L., and Worley, P. F. (1997). Homer: a protein that selectively binds metabotropic glutamate receptors. Nature 386, 284-288.

Bruel-Jungerman, E., Laroche, S., and Rampon, C. (2005). New neurons in the dentate gyrus are involved in the expression of enhanced longterm memory following environmental enrichment. Eur. J. Neurosci. 21, 513-521.

Buzsáki, G. (1996). The hippocampo-neocortical dialogue. Cereb. Cortex 6, 81-92.

Buzsáki, G. (2002). Theta oscillations in the hippocampus. Neuron 33, 325-340.

Buzsáki, G. (2005). Theta rhythm of navigation: link between path integration and landmark navigation, episodic and semantic memory. Hippocampus 15, 827-840.

Buzsáki, G., and Chrobak, J. J. (1995). Temporal structure in spatially organized neuronal ensembles: a role for interneuronal networks. Curr. Opin. Neurobiol. 5, 504-510.

Buzsáki, G., Csicsvari, J., Dragoi, G., Harris, K., Henze, D., and Hirase, H. (2002). Homeostatic maintenance of neuronal excitability by burst discharges in vivo. Cereb. Cortex 12, 893-899.

Chrobak, J. J., Lörincz, A., and Buzsáki, G. (2000). Physiological patterns in the hippocampoentorhinal cortex system. Hippocampus 10, 457-465.

Cole, A. J., Saffan, D. W., Baraban, J. M., and Worley, P. F. (1989). Rapid increase of an immediate early gene messenger RNA in hippocampal neurons by synaptic NMDA receptor activation. Nature 340, 474-476.

Collingridge, G. L., Kehl, S. J., and McLennan, H. (1983). Excitatory amino acids in synaptic transmission in the Schaffer collateral-commissural pathway of the rat hippocampus. J. Physiol. 334, 33-46.

Csicsvari, J., Hirase, H., Czurkó, A., Mamiya, A., and Buzsáki, G. (1999). Oscillatory coupling of hippocampal pyramidal cells and interneurons in the behaving rat. J. Neurosci. 19, 274-287.

Csicsvari, J., Jamieson, B., Wise, K. D., and Buzsáki, G. (2003). Mechanisms of gamma oscillations in the hippocampus of the behaving rat. Neuron 37, 311-322.

Dan, Y., and Poo, M. M. (2004). Spike timingdependent plasticity of neural circuits. Neuron 44, 23-30.

Duffy, S. N., Craddock, K. J., Abel, T., and Nguyen, P. V. (2001). Environmental enrichment modifies the PKA-dependence of hippocampal LTP and improves hippocampus-dependent memory. Learn. Mem. 8, 26-34.

Errington, M. L., Lynch, M. A., and Bliss, T. V. (1987). Long-term potentiation in the dentate gyrus: induction and increased glutamate release are blocked by $\mathrm{D}(-)$ aminophosphonovalerate. Neuroscience 20, 279-284.

Fell, J., Klaver, P., Lehnertz, K., Grunwald, T., Schaller, C., Elger, C. E., and Fernandez, G. (2001). Human memory formation is accompanied by rhinal-hippocampal coupling and decoupling. Nat. Neurosci. 4, 1159-1160.

Foster, T. C., Fugger, H. N., and Cunningham, S. G. (2000). Receptor blockade reveals a correspondence between hippocampal-dependent behavior and experience-dependent synaptic enhancement. Brain Res. 871, 39-43.

Fox, C. J., Russell, K. I., Wang, Y. T., and Christie, B. R. (2006). Contribution of NR2A and NR2B NMDA subunits to bidirectional synaptic plasticity in the hippocampus in vivo. Hippocampus 16, 907-915.

Frey, U., Frey, S., Schollmeier, F., and Krug, M. (1996). Influence of actinomycin D, a RNA synthesis inhibitor, on long-term potentiation in rat hippocampal neurons in vivo and in vitro. J. Physiol. 490, 703-711.

Frey, U., Huang, Y.-Y., and Kandel, E. R. (1993). Effect of cAMP simulates a late stage of LTP in hippocampal CA1 neurons. Science 260, 1661-1664.

Fries, P., Reynolds, J. H., Rorie, A. E., and Desimone, R. (2001). Modulation of oscillatory neuronal synchronization by selective visual attention. Science 291, 1560-1563.

Granado, N., Ortiz, O., Suárez, L. M., Martín. E. D., Ceña, V., Solís, J. M., and Moratalla, R. (2008). D1 but not D5 dopamine receptors are critical for LTP, spatial learning, and LTP-Induced arc and zif268 expression in the hippocampus. Cereb. Cortex 18, 1-12.

Gray, C. M., and Singer, W. (1989). Stimulus-specific neuronal oscillations in orientation columns of cat visual cortex. Proc. Natl. Acad. Sci. USA 86, $1698-1702$.

Hermann, C. S., Munk, M. H., and Engel, A. K. (2004). Cognitive functions of gamma-band activity: memory match and utilization. Trends Cogn. Sci. 8, 347-355.

Hölscher, C., Anwyl, R., and Rowan, M. J. (1997). Block of theta-burst-induced long-term potentiation by (1S,3S)-1-aminocyclopentane-1,3dicarboxylic acid: further evidence against long-term potentiation as a model for learning. Neuroscience 81, 17-22.

Hopfield, J. J. (1995). Pattern recognition computation using action potential timing for stimulus representation. Nature 376, 33-36.
Huang, Y. Y., Nguyen, P. V., Abel, T., and Kandel, E. R. (1996). Long-lasting forms of synaptic potentiation in the mammalian hippocampus. Learn. Mem. 3, 74-85.

Huerta, P. T., and Lisman, J. E. (1993). Heightened synaptic plasticity of hippocampal CA1 neurons during a cholinergically induced rhythmic state. Nature 364, 723-725.

Huerta, P. T., and Lisman, J. E. (1995). Bidirectional synaptic plasticity induced by a single burst during cholinergic theta oscillation in CA1 in vitro. Neuron 15, 1053-1063.

Hyman, J. M., Wyble, B. P., Goyal, V., Rossi, C. A., and Hasselmo, M. E. (2003). Stimulation in hippocampal region CA1 in behaving rats yields long-term potentiation when delivered to the peak of theta and long-term depression when delivered to the trough. J. Neurosci. 23, 11725-11731.

Kamondi, A., Acsády, L., Wang, X. J., and Buzsáki, G. (1998). Theta oscillations in somata and dendrites of hippocampal pyramidal cells in vivo: activity-dependent phase-precession of action potentials. Hippocampus 8, 244-261.

Kemp, A., and Manahan-Vaughan, D. (2005). The 5-hydroxytryptamine4 receptor exhibits frequency-dependent properties in synaptic plasticity and behavioural metaplasticity in the hippocampal CA1 region in vivo. Cereb. Cortex 15, 1037-1043.

Kemp, A., and Manahan-Vaughan, D. (2007). Hippocampal long-term depression: master or minion in declarative memory processes? Trends Neurosci. 30, 111-118.

Kemp, A., and Manahan-Vaughan, D. (2008). \{beta $\}-$ adrenoreceptors comprise a critical element in learning-facilitated long-term plasticity. Cereb. Cortex. 18, 968-977.

Klausberger, T., Magill, P.J., Márton, L. F., Roberts, J. D., Cobden, P. M., Buzsáki, G., and Somogyi, P. (2003). Brain-state- and cell-type-specific firing of hippocampal interneurons in vivo. Nature 421, 844-848.

Kneisler, T.B., and Dingledine, R. (1995). Spontaneous and synaptic input from granule cells and the perforant path to dentate basket cells in the rat hippocampus. Hippocampus 5, 151-164.

Kopp, C., Longordo, F., Nicholson, J. R., and Lüthi, A. (2006). Insufficient sleep reversibly alters bidirectional synaptic plasticity and NMDA receptor function. J. Neurosci. 26, 12456-12465.

Krug, M., Lössner, B., and Ott, T. (1984). Anisomycin blocks the late phase of long-term potentiation in the dentate gyrus of freely moving rats. Brain Res. Bull. 13, 39-42.

Kulla, A., and Manahan-Vaughan, D. (2002). Modulation by serotonin 5-HT(4) receptors of long-term potentiation and depotentiation in the dentate gyrus of freely moving rats. Cereb. Cortex 12, 150-162.

Lemon, N., and Manahan-Vaughan, D. (2006). Dopamine D1/D5 receptors gate the acquisition of novel information through hippocampal long-term potentiation and long-term depression. J. Neurosci. 26, 7723-7729.

Li, S., Cullen, W. K., Anwyl, R., and Rowan, M. J. (2003). Dopamine-dependent facilitation of LTP induction in hippocampal CA1 by exposure to spatial novelty. Nat. Neurosci. 6, 526-531. 
Li, S., Cullen, W. K., Anwyl, R., and Rowan, M. J. (2007). Muscarinic acetylcholine receptordependent induction of persistent synaptic enhancement in rat hippocampus in vivo. Neuroscience 144, 754-761.

Link, W., Konietzko, U., Kauselmann, G., Krug, M., Schwanke, B., Frey, U., and Kuhl, D. (1995). Somatodendritic expression of an immediate early gene is regulated by synaptic activity. Proc. Natl. Acad. Sci. USA 92, 5734-5738.

Lisman, J. E. (1999). Relating hippocampal circuitry to function: recall of memory sequences by reciprocal dentate-CA3 interactions. Neuron 22, 233-242.

Lisman, J. E., and Idiart, M. A. (1995). Storage of $7+/-2$ short-term memories in oscillatory subcycles. Science 267, 1512-1515.

Lømo, T. (2003). The discovery of long-term potentiation. Philos. Trans. R. Soc. Lond., B, Biol. Sci. 358, 617-620.

Lynch, M. A. (2004). Long-term potentiation and memory. Physiol. Rev. 84, 87-136.

Manahan-Vaughan, D. (1997). Group 1 and 2 metabotropic glutamate receptors play differential roles in hippocampal long-term depression and long-term potentiation in freely moving rats. J. Neurosci. 17, 3303-3311.

Manahan-Vaughan, D., and Braunewell, K. H. (2005). The metabotropic glutamate receptor, mGluR5, is a key determinant of good and bad spatial learning performance and hippocampal synaptic plasticity. Cereb. Cortex 15, 1703-1713.

Manahan-Vaughan, D., Braunewell, K. H., and Reymann, K. G. (1998). Subtype-specific involvement of metabotropic glutamate receptors in two forms of long-term potentiation in the dentate gyrus of freely moving rats. Neuroscience 86, 709-721.

Manahan-Vaughan, D., and Kulla, A. (2003). Regulation of depotentiation and long-term potentiation in the dentate gyrus of freely moving rats by dopamine D2-like receptors. Cereb. Cortex 13, 123-135.

Manahan-Vaughan, D., and Reymann, K. G. (1996). Metabotropic glutamate receptor subtype agonists facilitate long-term potentiation within a distinct time window in the dentate gyrus in vivo. Neuroscience 74, 723-731.

Martin, S. J. (2001). Activation of metabotropic glutamate receptors induces gamma frequency oscillations in the rat dentate gyrus in vivo. Neuropharmacology 40, 634-637.

McCartney, H., Johnson, A. D., Weil, Z. M., and Givens, B. (2004). Theta reset produces optimal conditions for long-term potentiation. Hippocampus 14, 684-687.

Messaoudi, E., Kanhema, T., Soulé, J., Tiron, A., Dagyte, G., da Silva, B., and Bramham, C. R. (2007). Sustained Arc/Arg3.1 synthesis controls long-term potentiation consolidation through regulation of local actin polymerization in the dentate gyrus in vivo. J. Neurosci. 27, 10445-10455.

Montgomery, S. M., and Buzsáki, G. (2007). Gamma oscillations dynamically couple hippocampal CA3 and CA1 regions during memory task performance. Proc. Natl. Acad. Sci. USA 104, 14495-14500.
Nguyen, P. V., Abel, T., and Kandel, E. R. (1994). Requirement of a critical period of transcription for induction of a late phase of LTP. Science 265, 1104-1107.

Niewoehner, B., Single, F. N., Hvalby, Ø., Jensen, V., Borgloh, S. M., Seeburg, P. H., Rawlins, J. N., Sprengel, R., and Bannerman, D. M. (2007). Impaired spatial working memory but spared spatial reference memory following functional loss of NMDA receptors in the dentate gyrus. Eur. J. Neurosci. 25, 837-846.

O’Keefe, J., and Recce, M. L. (1993). Phase relationship between hippocampal place units and the EEG theta rhythm. Hippocampus 3, 317-330.

Orr, G., Rao, G., Houston, F. P., McNaughton, B. L., and Barnes, C. A. (2001). Hippocampal synaptic plasticity is modulated by theta rhythm in the fascia dentata of adult and aged freely behaving rats. Hippocampus 11, 647-654.

Otani, S., and Abraham, W. C. (1989). Inhibition of protein synthesis in the dentate gyrus but not entorhinal cortex blocks the maintenance of long-term potentiation in rats. Neurosci. Lett. 106, 175-180.

Pavlides, C., Greenstein, Y. J., Grudman, M., and Winson, J. (1988). Long-term potentiation in the dentate gyrus is induced preferentially on the positive phase of theta-rhythm. Brain Res. 439, 383-387.

Penttonen, M., Kamondi, A., Acsady, L., and Buzsáki, G. (1998). Gamma frequency oscillation in the hippocampus of the rat: intracellular analysis in vivo. Eur. J. Neurosci. 10, 718-728.

Richter-Levin, G., Errington, M. L., Maegawa, H., and Bliss, T. V. (1994). Activation of metabotropic glutamate receptors is necessary for long-term potentiation in the dentate gyrus and for spatial learning. Neuropharmacology 33, 853-857.

Seager, M. A., Johnson, L. D., Chabot, E. S., Asaka, Y., and Berry, S. D. (2002). Oscillatory brain states and learning: Impact of hippocampal theta-contingent training. Proc. Natl. Acad. Sci. USA 99, 1616-1620.

Seidenbecher, T., Reymann, K. G., and Balschun, D. (1997). A post-tetanic time window for the reinforcement of long-term potentiation by appetitive and aversive stimuli. Proc. Natl. Acad. Sci. USA 94, 1449-1499.

Sik, A., Penttonen, M., and Buzsáki, G. (1997). Interneurons in the hippocampal dentate gyrus: an in vivo intracellular study. Eur. J. Neurosci. 9, 573-588.

Singer, W. (1993). Synchronization of cortical activity and its putative role in information processing and learning. Annu. Rev. Physiol. 55, 349-374.

Swanson-Park, J. L., Coussens, C. M., MasonParker, S. E., Raymond, C. R., Hargreaves, E. L., Dragunow, M., Cohen, A. S., and Abraham, W. C. (1999). A double dissociation within the hippocampus of dopamine D1/D5 receptor and beta-adrenergic receptor contributions to the persistence of long-term potentiation. Neuroscience 92, 485-497.

Traub, R. D., Bibbig, A., LeBeau, F. E. N., Buhl, E. H., and Whittington, M. A. (2004). Cellular mechanisms of neuronal population oscillations in the hippocampus in vitro. Annu. Rev. Neurosci. 27, 247-278.
Vanderwolf, C. H. (1969). Hippocampal electrical activity and voluntary movement in the rat. Electroencephalogr. Clin. Neurophysiol. 26, 407-418.

van Praag, H., Christie, B. R., Sejnowski, T. J., and Gage, F. H. (1999). Running enhances neurogenesis, learning, and long-term potentiation in mice. Proc. Natl. Acad. Sci. USA 96, 13427-13431.

Vertes, R. P. (2005). Hippocampal theta rhythm: a tag for short-term memory. Hippocampus 15, 923-935.

Vida, I., Bartos, M., and Jonas, P. (2006). Shunting inhibition improves robustness of gamma oscillations in hippocampal interneuron networks by homogenizing firing rates. Neuron 49, 107-117.

Wespatat, V., Tennigkeit, F., and Singer, W. (2004). Phase sensitivity of synaptic modifications in oscillating cells of rat visual cortex. J. Neurosci. 24, 9067-9075.

Whitlock, J. R., Heynen, A. J., Shuler, M. G., and Bear, M. F. (2006). Learning induces long-term potentiation in the hippocampus. Science 313, 1093-1097.

Whittington, M. A., Stanford, I. M., Colling, S. B., Jefferys, J. G. R., and Traub, R. D. (1997). Spatiotemporal patterns of $\mathrm{g}$ frequency oscillations tetanically induced in the rat hippocampal slice. J. Physiol. (Lond.) 502, 591-607.

Whittington, M. A., Traub, R. D., and Jefferys, J. G. (1995). Synchronized oscillations in interneuron networks driven by metabotropic glutamate receptor activation. Nature 373, 612-615.

Wisden, W., Errington, M. L., Williams, S., Dunnett, S. B., Waters, C., Hitchcock, D., Evan, G., Bliss, T. V., and Hunt, S. P. (1990). Differential expression of immediate early genes in the hippocampus and spinal cord. Neuron 4, 603-614.

Xu, L., Holscher, C., Anwyl, R., and Rowan, M. J. (1998). Glucocorticoid receptor and protein/ RNA synthesis-dependent mechanisms underlie the control of synaptic plasticity by stress. Proc. Natl. Acad. Sci. USA 95, 3204-3208.

Yin, Y., Edelman, G. M., and Vanderklish, P. W. (2002). The brain-derived neurotrophic factor enhances synthesis of Arc in synaptoneurosomes. Proc. Natl. Acad. Sci. USA 99, 2368-2373.

Ylinen, A., Soltesz, I., Bragin, A., Penttonen, M., Sik, A., and Buzsáki, G. (1995). Intracellular correlates of hippocampal theta rhythm in identified pyramidal cells, granule cells, and basket cells. Hippocampus 5, 78-90.

Received: 15 May 2008; accepted: 13 June 2008.

Citation: Front. Neurosci. (2008) 2, 1: 56-63. doi: 10.3389/neuro.01.010.2008

Copyright (C) 2008 Bikbaev and ManahanVaughan. This is an open-access article subject to an exclusive license agreement between the authors and the Frontiers Research Foundation, which permits unrestricted use, distribution, and reproduction in any medium, provided the original authors and source are credited. 